SRNL-STI-2009-00353

\title{
Development of Process Control Equations to Support Detoxification of Copper Using Natural Humate Amendments
}

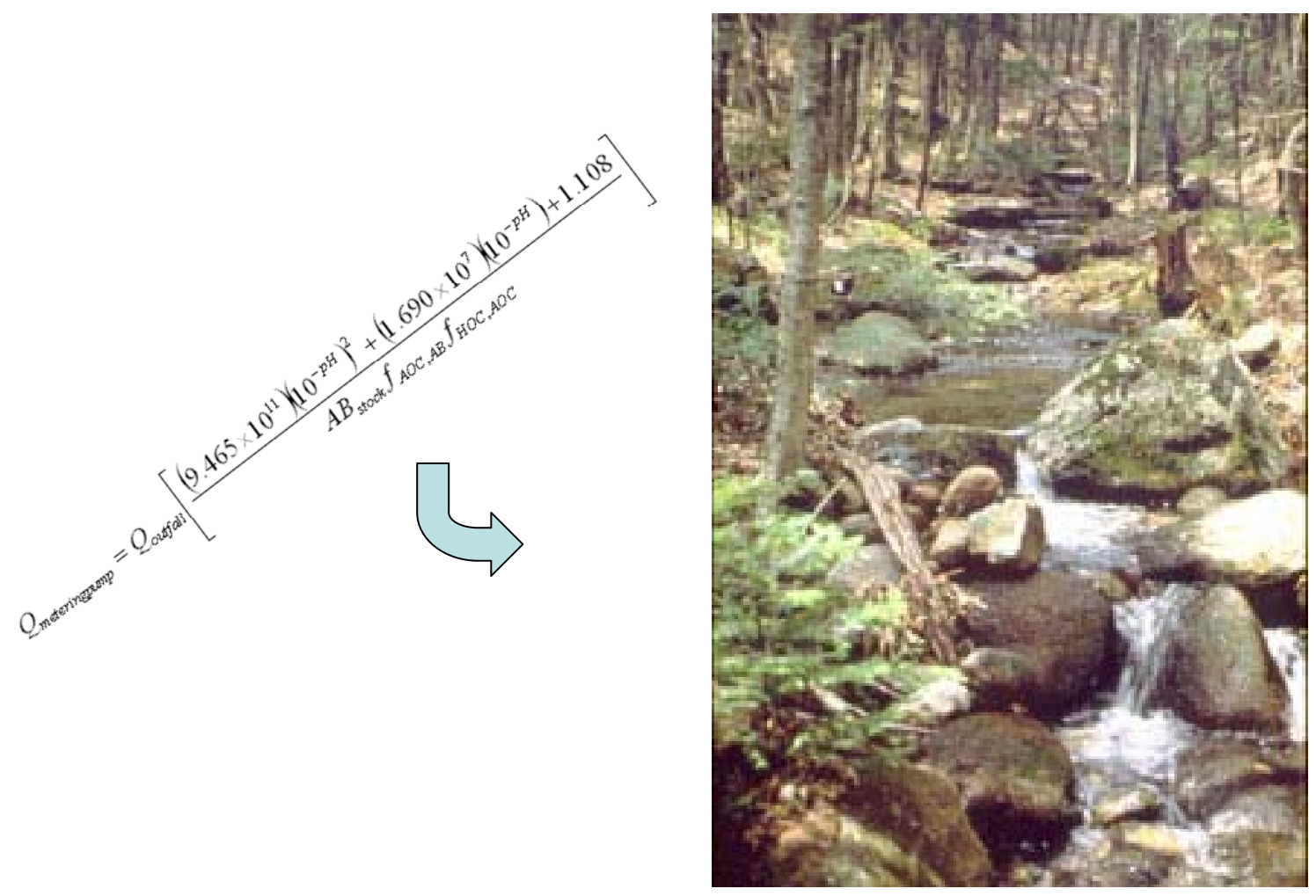

Brian B. Looney

Margaret R. Millings

Environmental Science and Biotechnology Division

Savannah River National Laboratory

Aiken SC 29808

This document was prepared in conjunction with work accomplished under

Contract No. DE-AC09-08SR22470 with the U.S. Department of Energy. 


\section{Disclaimer:}

This work was prepared under an agreement with and funded by the U.S. Government. The authors were careful with regard to the accuracy of the contents and interpretation. However, neither the U. S. Government or its employees, nor any of its contractors, subcontractors or their employees, makes any express or implied: 1 . warranty or assumes any legal liability for the accuracy, completeness, or for the use or results of such use of any information, product, or process disclosed; or 2. representation that such use or results of such use would not infringe privately owned rights; or 3 . endorsement or recommendation of any specifically identified commercial product, process, or service. Any views and opinions of authors expressed in this work do not necessarily state or reflect those of the United States Government, or its contractors, or subcontractors. 


\section{Development of Control Equations to Support Detoxification of Copper using Natural Humate Amendments}

\section{Table of Contents}

Executive Summary $\quad 1$

$\begin{array}{ll}\text { Introduction } & 2\end{array}$

Process Control Equation Development 3

Conceptual approach for control equation development 3

Determine target Humic Organic Carbon concentrations 5

Simplified mathematical relationship between humic $\begin{array}{ll}\text { organic carbon and } \mathrm{pH} & 8\end{array}$

Evaluate potential humate amendments and determine $\begin{array}{ll}\text { humic organic carbon content } & 10\end{array}$

a) Specify bulk amendment concentration in stock 10

b) Measure organic carbon content in bulk amendment fraction 10

c) Amendment organic carbon in stock solution 10

d) Determine amendment performance referenced to standard humic acid 12

e) Determine the humic organic carbon content of the amendments 19

Putting It Together -- The Overall Process Control Equation 20 


\section{Acronyms and notation}

$\mathrm{AB}_{\text {stock }}=$ bulk amendment in the stock solution (mg amendment / $\mathrm{L}$ of solution)

$\mathrm{AOC}_{\text {stock }}=$ amendment organic carbon in the stock solution (total organic carbon in the amendment in units of $\mathrm{mg} \mathrm{C} / \mathrm{L}$ )

$\mathrm{BLM}=$ Biotic Ligand Model

$\mathrm{CCC}=$ Criterion Continuous Concentration in $\mu \mathrm{g} \mathrm{Cu} / \mathrm{L}$ (this is the estimate of continuous copper concentration that results in projected long term, or chronic, ecosystem impacts)

$\mathrm{CMC}=$ Criterion Maximum Concentration in $\mu \mathrm{g} \mathrm{Cu} / \mathrm{L}$ (this is the estimate of the copper concentration that results in projected short-term ecosystem impacts)

$\mathrm{Cu}=$ copper

DHEC = SC Department of Health and Environmental Control

$\mathrm{DOC}=$ dissolved organic carbon $(\mathrm{mg} \mathrm{C} / \mathrm{L})$

EPA = US Environmental Protection Agency

$\mathrm{FAV}=$ Final Acute Value in $\mu \mathrm{g} / \mathrm{L}$ (this is copper concentration that results in measurable acute impacts)

gpm = gallons per minute

gph = gallons per hour

$\mathrm{HOC}=$ humic organic carbon (the organic carbon in the amendment that is contributed by humic acid and similar compounds that complex copper)

$\mathrm{HOC}_{\text {dose }}=$ required concentration of HOC in the outfall to mitigate copper toxicity (mg HOC / L)

OMRI = Organic Materials Review Institute

PLC = programmable logic controller

$\mathrm{Q}_{\text {outfall }}=$ flow of water in target outfall $(\mathrm{gpm})$

$\mathrm{Q}_{\text {meteringpump }}=$ flow of metering pump (either gpm or gph, see text)

SRS = Savannah River Site

SRNL = Savannah River National Laboratory

TU = Acute Toxic Units

WHAM $=$ Windermere Humic Aquatic Model

$f_{\mathrm{AOC}, \mathrm{AB}}=$ fraction organic carbon in the amendment (the ratio of the mass of organic

carbon in the amendment to the total mass of bulk amendment)

$f_{\mathrm{HB}, \mathrm{AB}}=$ fraction bulk humic acid content in the bulk amendment (the ratio of the mass of equivalent standard humic acid to the total mass of bulk amendment)

$f_{\text {HOC,AOC }}=$ fraction of humic organic carbon in the amendment organic carbon (the ratio of the mass of humic organic carbon to amendment organic carbon)

$f_{\mathrm{HOC}, \mathrm{HB}}=$ fraction humic organic carbon in the bulk humic acid (the ratio of the mass of carbon in humic acid to the total mass of bulk humic acid) 


\section{Executive Summary}

Robust control equations are needed to support implementation of an innovative copper detoxification process to assure that water discharged to the $\mathrm{H}-12$ Outfall is protective of the ecology in the receiving stream. The equations, based on the EPA Biotic Ligand Model (BLM), establish the amount of humate amendment to achieve ecosystem protection goals. Humate binds and detoxifies copper; the amount of amendment needed is a function of $\mathrm{pH}$ and outfall flow. After analyzing a variety of options, we developed a polynomial equation, using hydrogen ion concentration as the independent variable, to determine target amendment concentration. This polynomial provides good performance over a wide $\mathrm{pH}$ range and was superior to various alternatives. When mathematically combined with measured outfall flow rate and the specific measured properties of various brands of potential amendments, the polynomial provides for high-quality and "realtime” process control. The final-combined equation is suitable for use by an industry standard programmable logic controller (PLC), so that data from sensors may be used to modulate the amendment delivery/dosing pump.

The final process control equation is depicted below. Required sensor/monitor inputs ( $\mathrm{pH}$ and outfall flow) are shown above the hypothetical "controller box" and the required information from laboratory measurements are designated below the box. Definition of the various terms, units* and values for the measured coefficients are found in the appropriate sections of the document:

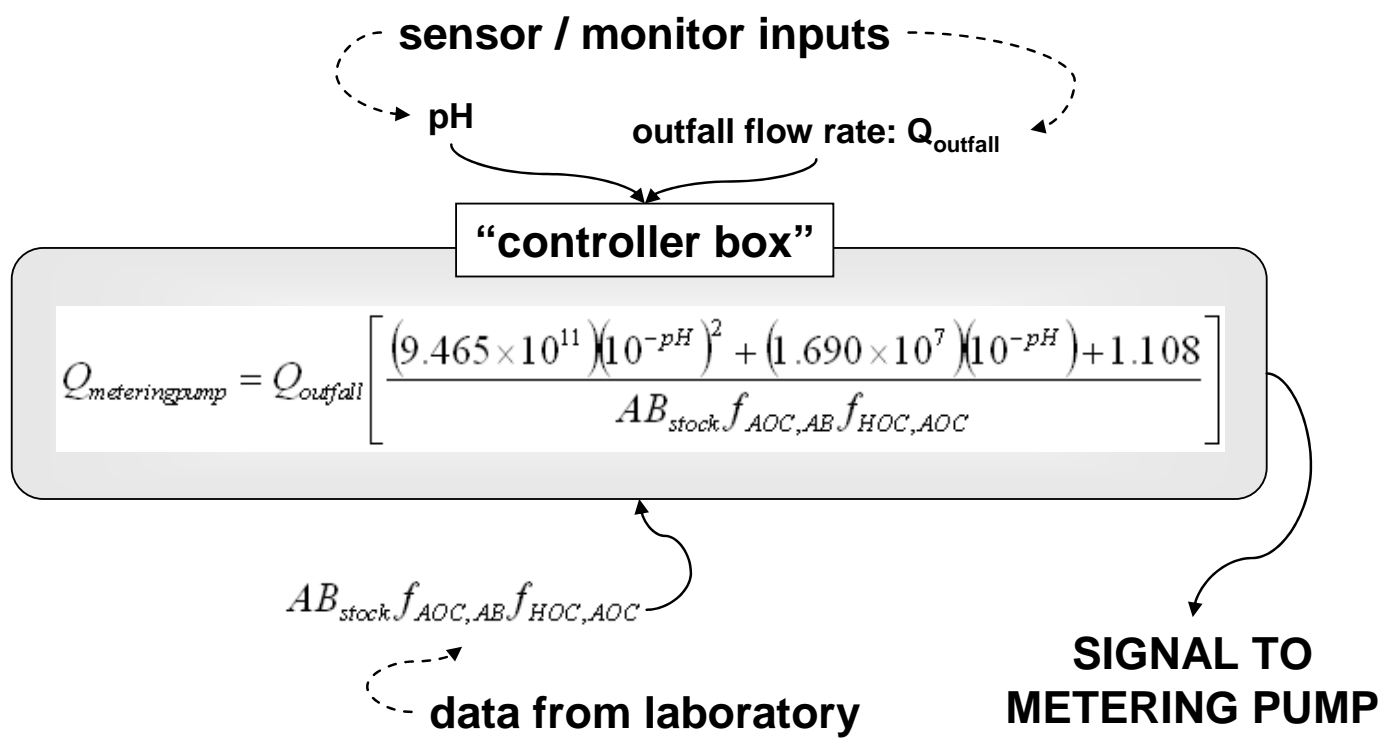

* Note that this equation results in a metering pump flow in the same units as the outfall flow (i.e., gpm). For a metering pump flow in traditional gph units, the result would be multiplied by 60 . 


\section{Introduction}

Recent scientific research and changes in regulatory policies have led to reductions in the allowable discharges of several contaminant metals, including copper, into surface water. Low target concentrations and variable outfall conditions challenge the efficacy of traditional treatment technologies such as ion exchange. In reviewing various treatment options, scientists and engineers at the Savannah River Site (SRS) developed a treatment strategy focusing on toxicity reduction (rather than the removal of the copper) and demonstrated that the method is viable and promising for mitigating copper toxicity. The resulting outfall chemistry protects the ecosystem in the receiving stream in a manner that is equal to, or better than, technologies that remove copper to the emerging regulatory levels. Further, the proposed toxicity reduction strategy results in collateral beneficial changes in outfall water chemistry such that the outfall more closely matches the chemistry of natural streams for key parameters such as the dissolved organic carbon (DOC).

The detoxification process is based on the EPA BLM. Specifically, modeling indicates that copper toxicity can be mitigated by modest additions of natural organic carbon and that the amount of amendment needed can be determined based on $\mathrm{pH}$ and stream flow. The organic carbon amendments proposed for the treatment/detoxification process are extracts of natural materials that are produced for use in organic agriculture. These extracts are known by several common names such as potassium humate, soluble humic acid, and a variety of brand trademarks. When used to reduce ecosystem toxicity in surface water, these amendments bind copper and compete with the biological receptor sites, resulting in a reduction of impacts to key food chain organisms such as the Daphnia (“water flea”).

Design and implementation of the process is straightforward. The core equipment consists of storage tank(s), $\mathrm{pH}$ sensor(s), outfall flow monitor(s), variable speed pump(s), and a programmable logic controller (PLC). The PLC collects information on $\mathrm{pH}$ and outfall flow, and modulates the pump flow rate to meter the correct amount of amendment into the outfall. A mathematical relationship, or control equation, is programmed into the PLC and serves as the basis of the operation. A summary of the development of, and key documentation for, the process control equation is provided below. 


\section{Process Control Equation Development}

\section{Overall Conceptual Approach}

The Savannah River National Laboratory (SRNL) investigated the effect of humate ("soluble humic acid") addition on copper speciation and the associated toxicity of the water. Consistent with recent regulatory guidance, the evaluation assessed potential effluent toxicity using the EPA Biotic Ligand Model (BLM) Windows Interface, version 2.2.1, by HydroQual, Inc. Baseline model runs using measured chemistry for the H-12 Outfall at the DOE Savannah River Site (Millings et al., 2008) were supplemented by model runs in which humic acid amendment was "added" to reduce copper toxicity. In these supplemental runs, the baseline chemistry was kept constant and the humic organic carbon (dissolved organic assumed to be $100 \%$ humic acid) was varied to determine the minimum required amendment dose (humic acid concentration) that assures that the whole effluent meets regulatory requirements for protection of the stream at the highest expected outfall copper concentrations. In later experiments using a copper electrode, the mechanism of the copper toxicity reduction was confirmed by titrating "free" copper using humate amendments. These experiments corroborated the BLM results and provided amendment specific coefficients for the process control equation.

The BLM calculations provided the fundamental underpinnings for the process control equation and were performed as the first of a series of organized steps. The entire development sequence consisted of the following modeling, laboratory, and data analysis activities: 1) Determine target humic organic carbon, HOC, concentrations using the BLM model, 2) develop a simplified mathematical relationship between HOC and $\mathrm{pH}, 3$ ) evaluate potential humate amendments and determine their humic acid content and HOC content, and 4) combine all of the information into an overall control equation that accounts for $\mathrm{pH}$, outfall flow, and selected amendment. As depicted in Figure 1, the final product of these steps is a responsive and robust equation for process control. 


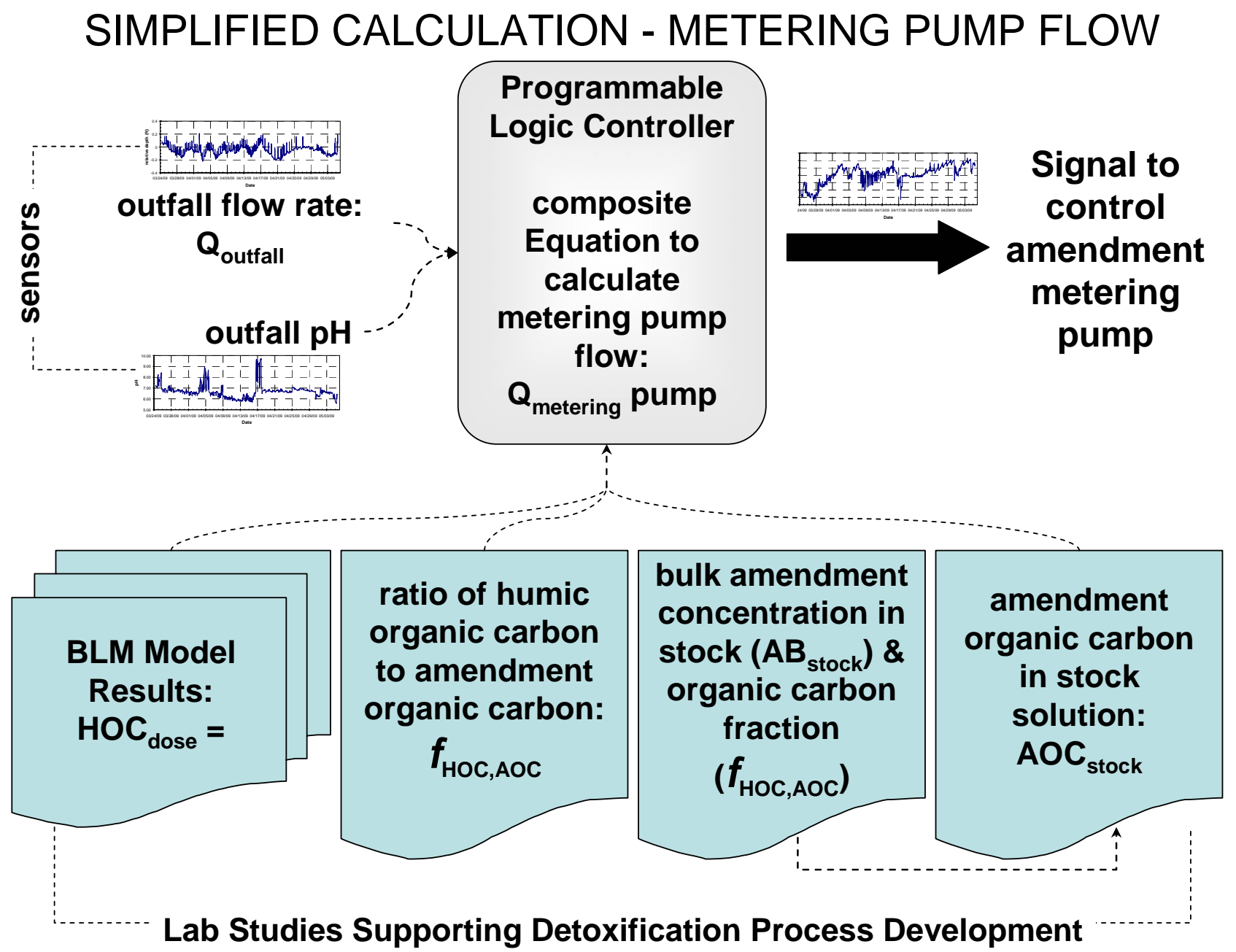

Figure 1. Graphical depiction of copper detoxification process control and the technical and modeling basis of the final equation 


\section{Determine Target Humic Organic Carbon Concentrations}

Version 2.2.1, the approved version of the BLM for use in making outfall water quality decisions, focuses only on the "Instantaneous WQC Calculations" for copper. The output for this version provides a criteria report with the following parameters (HydroQual, Inc, 2007):

- Final Acute Value (FAV) in ug/L (this is the model estimate of copper concentration that would result in measurable acute impacts)

- CMC or Criterion Maximum Concentration in ug/L, which is determined by dividing the FAV by 2 (based on EPA and SC DHEC guidance, this is the estimate of the copper concentration that would result in short-term ecosystem impacts)

- CCC or Criterion Continuous Concentration in ug/L, which is the calculated chronic concentration and is determined by dividing the FAV by ACR - where ACR is the acute-to-chronic ratio (the CCC is the model estimate of continuous copper concentration that would result in long term, or chronic, ecosystem impacts)

- $\mathrm{Cu}$ in ug/L, which is the amount of total dissolved copper measured in the effluent (this value is used along with the CMC and calculate the Acute Toxic Units)

- Acute Toxic Units (TU), which is a ratio of the total dissolved copper to the CMC (TU values greater than 1 indicate that measured copper level is above the CMC and the magnitude indicates the degree of exceedance of the CMC)

As expected, the baseline water BLM output exhibited low CCC and CMC values for all of the certified and screening sample events (Millings et al., 2008) since little DOC and hardness are present in the water (Table 1). Importantly, the BLM runs for baseline data suggested that the historical outfall limits $(25 \mu \mathrm{g} / \mathrm{L}$ average and $35 \mu \mathrm{g} / \mathrm{L}$ maximum) are not fully protective of the ecosystem in the receiving ephemeral stream. Copper at these historical concentration limits resulted in estimated TU ratios ranging from about 3 to 21, depending on the specific effluent chemistry.

The input data and results from the humate detoxification modeling are shown in Table 2. CCC values are highlighted and are $25 \mathrm{ug} / \mathrm{L}$ (or slightly above). The amount of dissolved organic carbon amendment (mg DOC / L) added in order to generate the calculated CCC is included in the table. Note that this set of modeling runs assumes that the $100 \%$ of the DOC is associated with humic acid so that the values listed represent the humic organic carbon, HOC, requirements. BLM results show that HOC values of approximately $22 \mathrm{mg}$ DOC/L or less are needed to achieve CCC values of $25 \mathrm{ug} / \mathrm{L}$ at all outfall $\mathrm{pH}$ values $>5.9$. At a typical outfall $\mathrm{pH}$ (approximately 7.3) the DOC dose required to mitigate toxicity and achieve the ecological objectives is approximately $2.4 \mathrm{mg}$ DOC / L. Note that for all DOC amended cases, the associated CMC values are above $35 \mathrm{ug} / \mathrm{L}$, so that the quantity of DOC added to achieve the CCC goal is sufficient to achieve the CMC goal. 
Table 1. Baseline BLM Model Results for Certified and Screening Samples at the SRS H-12 Outfall

\begin{tabular}{|c|c|c|c|c|c|c|}
\hline Site Label & $\begin{array}{c}\text { Sample } \\
\text { Label }\end{array}$ & $\begin{array}{c}\text { Final Acute } \\
\text { Value (FAV), } \\
\mathbf{\mu g / L}\end{array}$ & $\begin{array}{c}\text { Criterion } \\
\text { Maximum } \\
\text { Concentration } \\
\text { (CMC), } \mathbf{\mu g} / \mathbf{L}\end{array}$ & $\begin{array}{c}\text { Criterion } \\
\text { Continuous } \\
\text { Concentration } \\
\text { (CCC), } \mathbf{\mu g} / \mathbf{L}\end{array}$ & $\begin{array}{c}\mathbf{C u} \\
\mathbf{u g} / \mathbf{L}\end{array}$ & $\begin{array}{c}\text { Acute } \\
\text { Toxic } \\
\text { Units }\end{array}$ \\
\hline $\begin{array}{c}\text { H-12 } \\
\text { Certified }\end{array}$ & $\begin{array}{c}3-28-07 \\
\text { sample }\end{array}$ & 6.93 & 3.47 & 2.15 & 4.9 & 1.41 \\
\hline $\begin{array}{c}\text { H-12 } \\
\text { Certified }\end{array}$ & $\begin{array}{c}4-10-07 \\
\text { sample }\end{array}$ & 20.16 & 10.08 & 6.26 & 6.8 & 0.67 \\
\hline $\begin{array}{c}\text { H-12 } \\
\text { Screening }\end{array}$ & Median & 3.28 & 1.64 & 1.02 & 7.65 & 4.67 \\
\hline
\end{tabular}

Table 2. Input and output information for optimized model runs to determine target dose requirements Input Data

\begin{tabular}{|c|c|c|c|c|c|c|c|c|c|c|c|c|c|}
\hline Run & $\begin{array}{c}\text { Temperature } \\
\text { (C) }\end{array}$ & $\mathrm{pH}$ & $\mathrm{Cu}(\mu \mathrm{g} / \mathrm{L})$ typical & DOC (mg/L) & HA\% & $\begin{array}{c}\mathrm{Ca} \\
(\mathrm{mg} / \mathrm{L})\end{array}$ & $\begin{array}{c}\mathrm{Mg} \\
(\mathrm{mg} / \mathrm{L})\end{array}$ & $\begin{array}{c}\mathrm{Na} \\
(\mathrm{mg} / \mathrm{L})\end{array}$ & $\begin{array}{c}\mathrm{K} \\
(\mathrm{mg} / \mathrm{L})\end{array}$ & $\begin{array}{l}\text { Sulfate } \\
\text { (mg/L) }\end{array}$ & $\begin{array}{c}\mathrm{Cl} \\
\text { (mg/L) }\end{array}$ & $\begin{array}{c}\text { Alkalinity } \\
\text { (mg/L as } \\
\text { CaCo3) }\end{array}$ & $\mathrm{S}$ (mg/L) \\
\hline Optimized pH - 7.3 & 18 & 7.3 & 6.8 & 2.10 & 100 & 2.1 & 0.20 & 8.19 & 1.02 & 7.5 & 2.0 & 12.0 & $1 \times 10^{-10}$ \\
\hline Optimized pH - 8 & 18 & 8 & 6.8 & 1.35 & 100 & 2.1 & 0.20 & 8.19 & 1.02 & 7.5 & 2.0 & 13.0 & $1 \times 10^{-10}$ \\
\hline Optimized pH - 7 & 18 & 7 & 6.8 & 2.85 & 100 & 2.1 & 0.20 & 8.19 & 1.02 & 7.5 & 2.0 & 11.0 & $1 \times 10^{-10}$ \\
\hline Optimized pH - 6.5 & 18 & 6.5 & 6.8 & 6.15 & 100 & 2.1 & 0.20 & 8.19 & 1.02 & 7.5 & 2.0 & 9.0 & $1 \times 10^{-10}$ \\
\hline Optimized pH - 6 & 18 & 6 & 6.8 & 19.1 & 100 & 2.1 & 0.20 & 8.19 & 1.02 & 7.5 & 2.0 & 7.0 & $1 \times 10^{-10}$ \\
\hline Optimized pH - 5.5 & 18 & 5.5 & 6.8 & 64.0 & 100 & 2.1 & 0.20 & 8.19 & 1.02 & 7.5 & 2.0 & 5.0 & $1 \times 10^{-10}$ \\
\hline
\end{tabular}

notes: modified 6-30-08; run using BLM version 2.2.1; HA set to $100 \%$ \& DOC optimized by iteration so that Criterion Continuous Concentration $\sim 25$ ug/L

\begin{tabular}{|c|c|c|c|c|c|}
\cline { 2 - 6 } \multicolumn{1}{c|}{ Output Data } & $\begin{array}{c}\text { Final Acute } \\
\text { Value } \\
(\mathrm{FAV})\end{array}$ & $\begin{array}{c}\text { Criterion } \\
\text { Maximum } \\
\text { Concentration } \\
(\mathrm{CMC})\end{array}$ & $\begin{array}{c}\text { Criterion } \\
\text { Continuous } \\
\text { Concentration } \\
(\mathrm{CCC})\end{array}$ & $\begin{array}{c}\text { Typical } \\
\text { measured } \\
\text { Copper } \\
(\mathrm{Cu})\end{array}$ & $\begin{array}{c}\text { Acute } \\
\text { Toxic Units } \\
(\mathrm{TU})\end{array}$ \\
\hline Run & $\mu \mathrm{g} / \mathrm{L}$ & $\begin{array}{c}\mathrm{FAV} / 2, \\
\mu \mathrm{g} / \mathrm{L}\end{array}$ & $\begin{array}{c}\text { FAV/ACR, } \\
\mu \mathrm{g} / \mathrm{L}\end{array}$ & $\mu \mathrm{g} / \mathrm{L}$ & $\mathrm{Cu} / \mathrm{CMC}$ \\
\hline Optimized pH - 7.3 & 80.96 & 40.48 & $\mathbf{2 5 . 1 4}$ & 6.8 & 0.17 \\
\hline Optimized pH - & 80.70 & 40.35 & $\mathbf{2 5 . 0 6}$ & 6.8 & 0.17 \\
\hline Optimized $\mathrm{pH}-7$ & 81.59 & 40.80 & $\mathbf{2 5 . 3 4}$ & 6.8 & 0.17 \\
\hline Optimized $\mathrm{pH}-6.5$ & 81.21 & 40.61 & $\mathbf{2 5 . 2 2}$ & 6.8 & 0.17 \\
\hline Optimized $\mathrm{pH}-6$ & 80.83 & 40.42 & $\mathbf{2 5 . 1 0}$ & 6.8 & 0.17 \\
\hline Optimized $\mathrm{pH}-5.5$ & 80.83 & 40.42 & $\mathbf{2 5 . 1 0}$ & 6.8 & 0.17 \\
\hline
\end{tabular}


Note that the target concentrations from the model are slightly conservative, since these values do not take credit for the DOC typically present in the outfall (approximately 1 to $3 \mathrm{mg} \mathrm{C} \mathrm{/} \mathrm{L} \mathrm{of} \mathrm{undifferentiated} \mathrm{DOC)} \mathrm{and} \mathrm{the} \mathrm{targets} \mathrm{assume} \mathrm{that} \mathrm{the} \mathrm{all} \mathrm{of} \mathrm{the} \mathrm{required}$ DOC needs to be added in the form of high quality and high humic-content amendment.

A follow-up sensitivity analysis was conducted to verify the conceptual model that $\mathrm{pH}$ and DOC are the primary chemical variables that impact copper toxicity. The sensitivity study varied the solution concentration for each parameter around the nominal values in the optimized model runs ( $5 x$ and $0.2 x$ ), leaving all other parameters the same, and documented the impact on the calculated CCC. Figure 2 provides a graphical summary of the results. In this figure, the various changes are plotted as a ratio of the new CCC to the original CCC - values near "1.0" represent little change and little sensitivity to a particular parameter and larger or smaller numbers indicate a high sensitivity. The graph confirms that $\mathrm{pH}$ and DOC are the primary parameters that control copper toxicity and the remaining chemical parameters have minimal impact on copper toxicity, even when large excursions of concentration (e.g., 5x) are assumed. This evaluation supports the development of a process control equation in which the target amendment concentration is determined based on real-time monitoring of $\mathrm{pH}$.

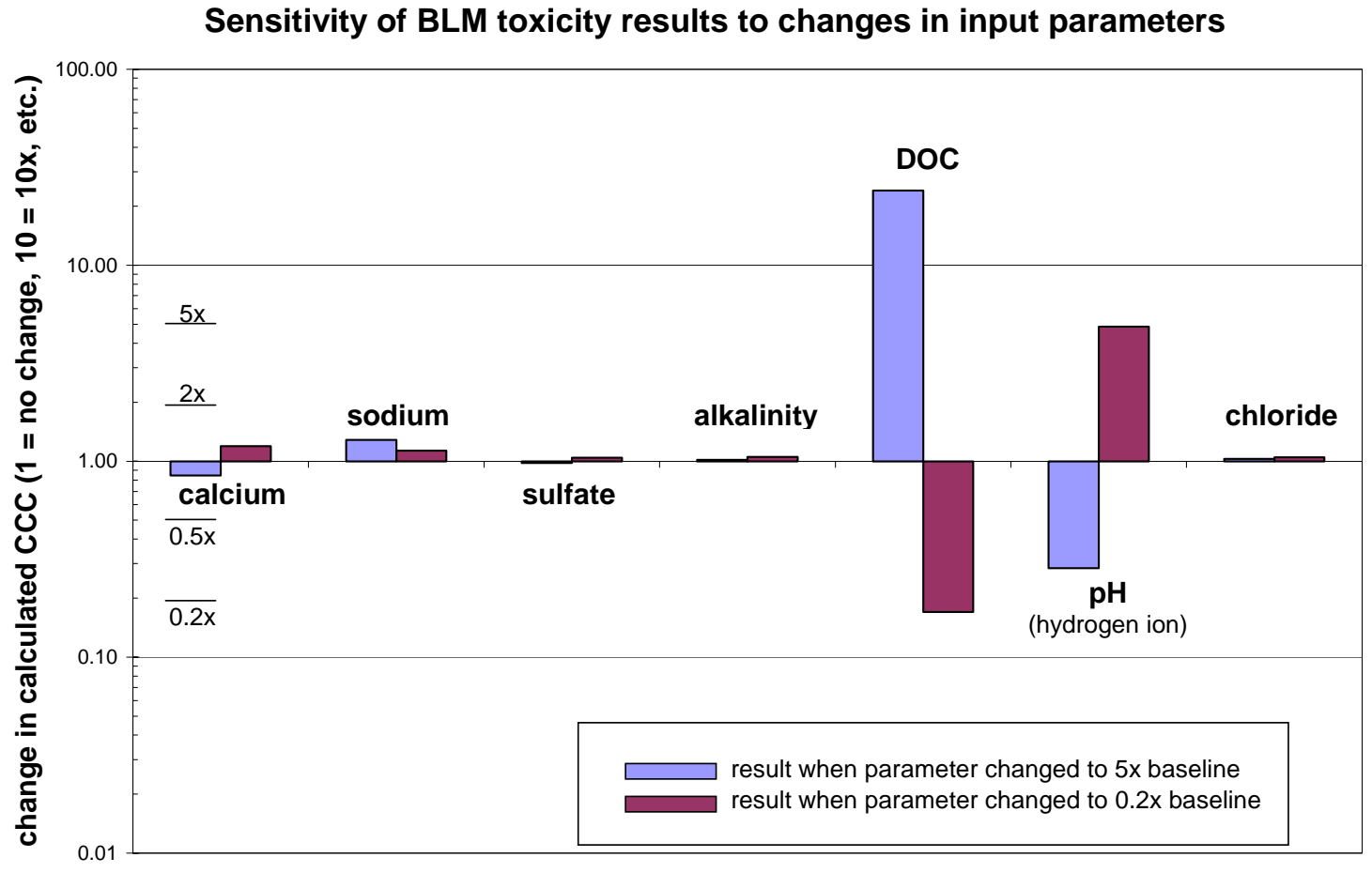

Figure2. Sensitivity analysis documenting the impacts of large changes in individual water quality parameters on predicted copper toxicity 


\section{Simplified mathematical relationship between humic organic carbon and $\mathrm{pH}$}

The BLM modeling confirmed that $\mathrm{pH}$ and DOC are the primary parameters that control ecological toxicity of copper. Further, the modeling supports developing a process that mitigates copper toxicity based on $\mathrm{pH}$, an easily monitored parameter, using standard process equipment to add the required quantity of humic organic carbon. To facilitate reasonable implementation, the BLM modeling results need to be captured in a mathematical relationship suitable for use in a programmable logic controller. The core of the equation is a defensible closed form equation that relates $\mathrm{pH}$ to humic organic carbon. The process of examining various potential relationships indicated that equations that are based on hydrogen ion concentration $\left(\left[\mathrm{H}^{+}\right]=10^{-\mathrm{pH}}\right)$ as the independent variable were simpler and provided superior predictions (compared to equations that directly use $\mathrm{pH}$ as the independent variable). Two of the best fits were a simple linear regression and a simple second order polynomial:

linear regression:

$$
\mathrm{HOC}_{\text {dose }}=1.993 \times 10^{7}\left[\mathrm{H}^{+}\right]+0.521\left(\mathrm{r}^{2}=0.998\right)
$$

polynomial:

$$
\mathrm{HOC}_{\text {dose }}=9.465 \times 10^{11}\left[\mathrm{H}^{+}\right]^{2}+1.690 \times 10^{7}\left[\mathrm{H}^{+}\right]+1.108\left(\mathrm{r}^{2}=0.999\right)
$$

$\mathrm{HOC}_{\text {dose }}$ is the required concentration of humic organic carbon (in mg HOC / L) needed to mitigate ecological toxicity (achieving a CCC of $25 \mu \mathrm{gCu} / \mathrm{L}$ ) and $\left[\mathrm{H}^{+}\right]$is the hydrogen ion concentration (this can be replaced by $10^{-\mathrm{pH}}$ as needed to relate the equation to the output of a $\mathrm{pH}$ probe). Figure 3 provides graphical representations of the above equations. The symbols in Figure 3 are plotted from the data listed in the Table 2 above and the lines represent the model fits for the polynomial and the linear equations as noted. The $\mathrm{x}$ axis is the hydrogen ion concentration; reference lines designating specific $\mathrm{pH}$ values between 5.5 and 7.5 are provided to assist in using the graphs. While both of the simple equations provide a good correlation to the BLM model results based on $\mathrm{r}^{2}$, the linear formulation exhibited relatively significant bias and HOC dosing underpredictions at $\mathrm{pH}$ values above 7 (as noted in Figure 3b). The polynomial provided robust and accurate dosing predictions over the entire $\mathrm{pH}$ range (Figure 3a) and is compatible with the capabilities of most standard PLCs. Thus, this equation was selected to serve as the core calculation in the process control equation. 


\section{a) polynomial equation}

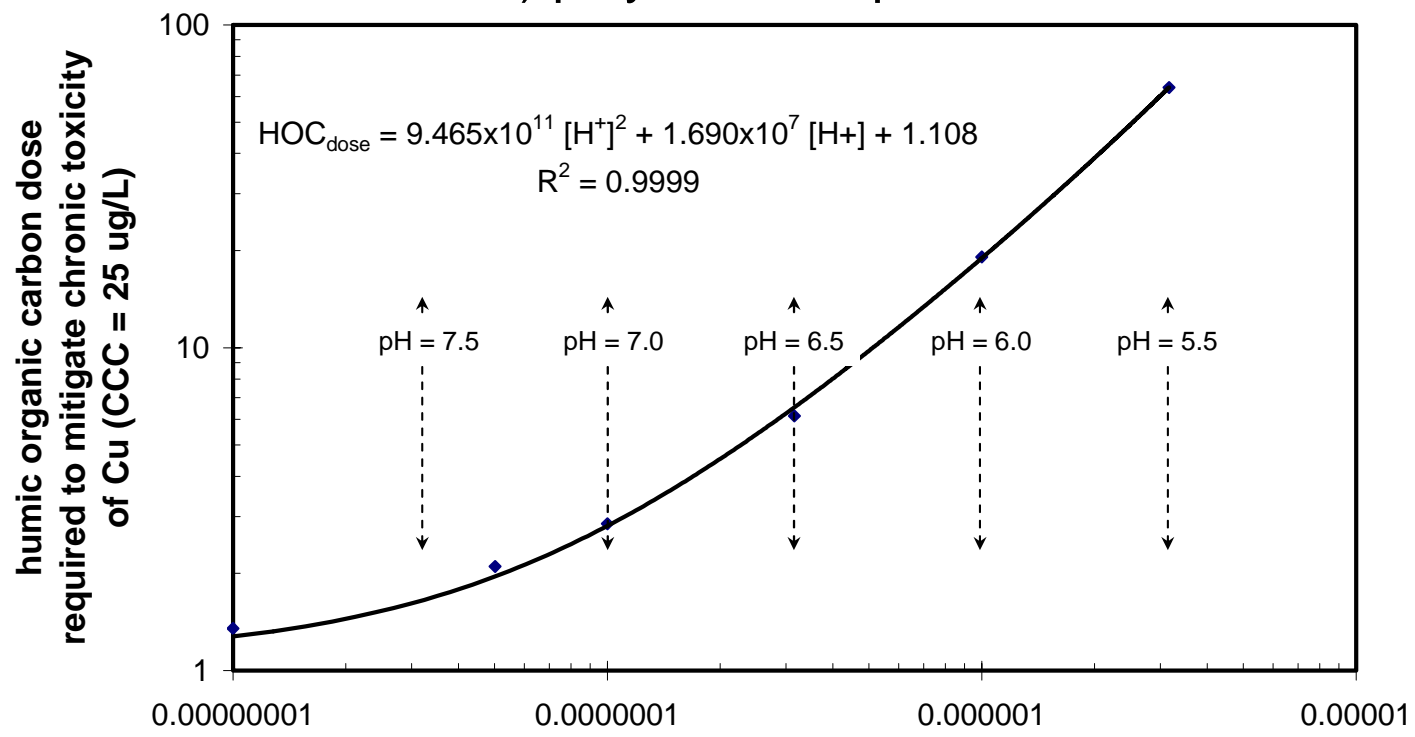

b) linearized equation

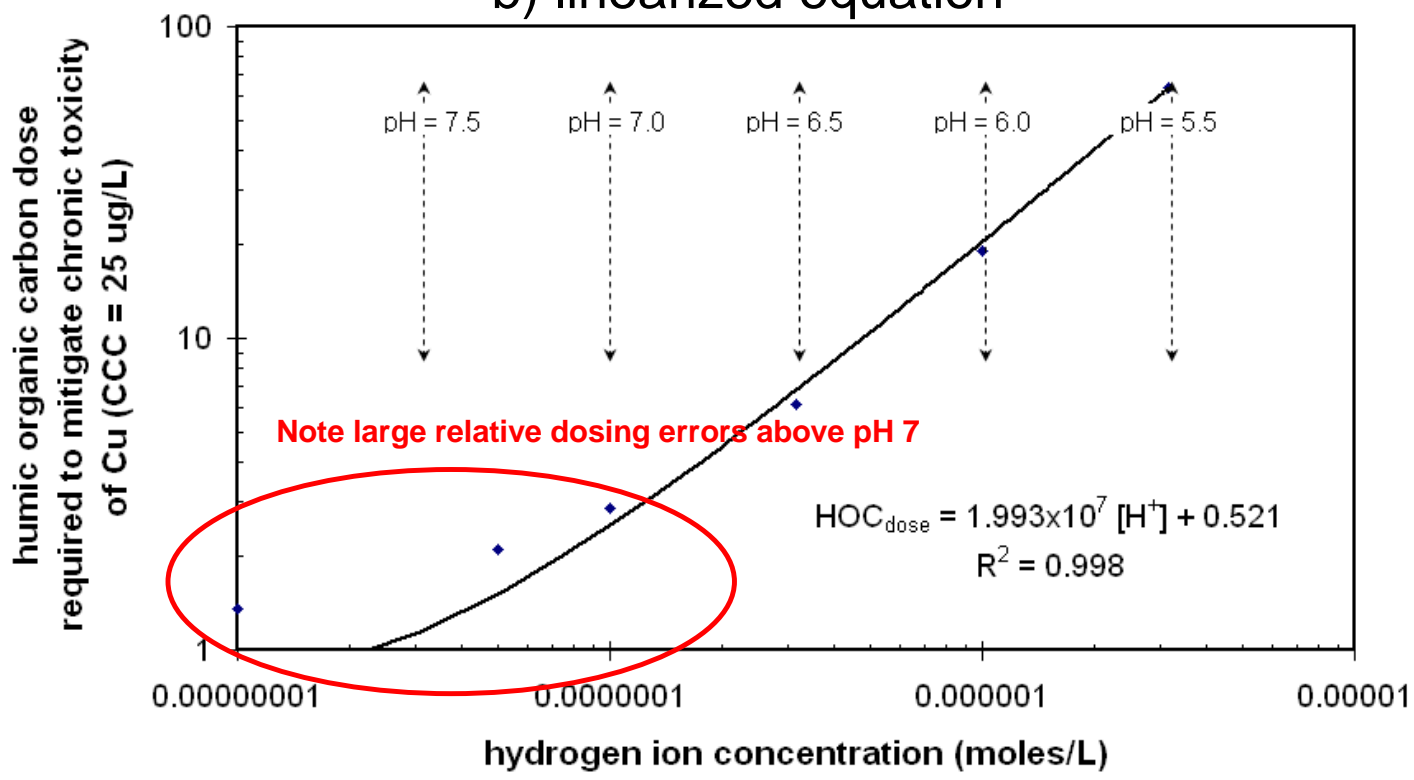

Figure 3. Comparison of alternative mathematical representations of the BLM results for copper detoxification - both graphs establish humic organic carbon dose required to meet toxicity reduction goals as a function of hydrogen ion concentration $-\mathrm{a}$ ) polynomial regression, and b) linear regression 


\section{Evaluate potential humate amendments and determine humic organic carbon content}

Humate amendments are natural products that are derived and extracted from various sources and which are subject to varying degrees of processing. A selection of commercially available amendments was identified for testing. Each amendment was characterized in terms of solubility, $\mathrm{pH}$, organic content and other bulk parameters (Millings et al., 2008). To effectively apply the proposed humate based copper detoxification - in which we have defined a relationship between HOC and $\mathrm{pH}-$ the humic acid content of potential amendments must be determined. Importantly, to assure consistency with the BLM the HOC most be normalized to the "standard humic acid" whose characteristics are built into the BLM. We performed a series of activities with potential amendments to quantitatively determine their performance normalized to standard humic acid and to capture this information in coefficients that can be utilized in the final control equation. These steps are depicted in Figure 4. Each of the steps (a-f) is described below. The coefficients developed for the tested amendments are provided in Table 3.

a) Specify bulk amendment concentration in stock ( $\mathrm{AB}_{\text {stock}}$. Based on the solubility of the amendment and the logistics of handling and storage, a nominal bulk amendment concentration for a stock solution was determined. This concentration $\left(\underline{A B}_{s t o c k}\right)$ is in units of mg bulk amendment / $\mathrm{L}$ of solution. Differences in this parameter are related to the specific extraction and processing steps used in preparing the humate for delivery.

b) Measure organic carbon content in bulk amendment fraction $\left(f_{\mathrm{AOC}, \mathrm{AB}}\right)$. Samples of each amendment were diluted and analyzed to determine the organic carbon content. This parameter represents the ratio of the mass of organic carbon in the amendment to mass of bulk amendment. The data were originally reported in Millings et al. (2008); these data have been updated due to additional measurements and the results used to develop the process control equation are provided in Table 3.

c) Amendment organic carbon in stock solution (AOC stock $_{2}$. If desired, the concentration of organic carbon in the stock solution can be calculated as follows:

$$
\mathrm{AOC}_{\text {stock }}=\left(\mathrm{AB}_{\text {stock }}\right)\left(f_{\mathrm{AOC}, \mathrm{AB}}\right)
$$

Note that this parameter is simply a combination of the previous measurements and the process control equation can use either the combined or separate parameters. As designated by the dashed box, we have included the separate parameters in the process control equation for clarity and to support and simplify amendment procurement specification. 


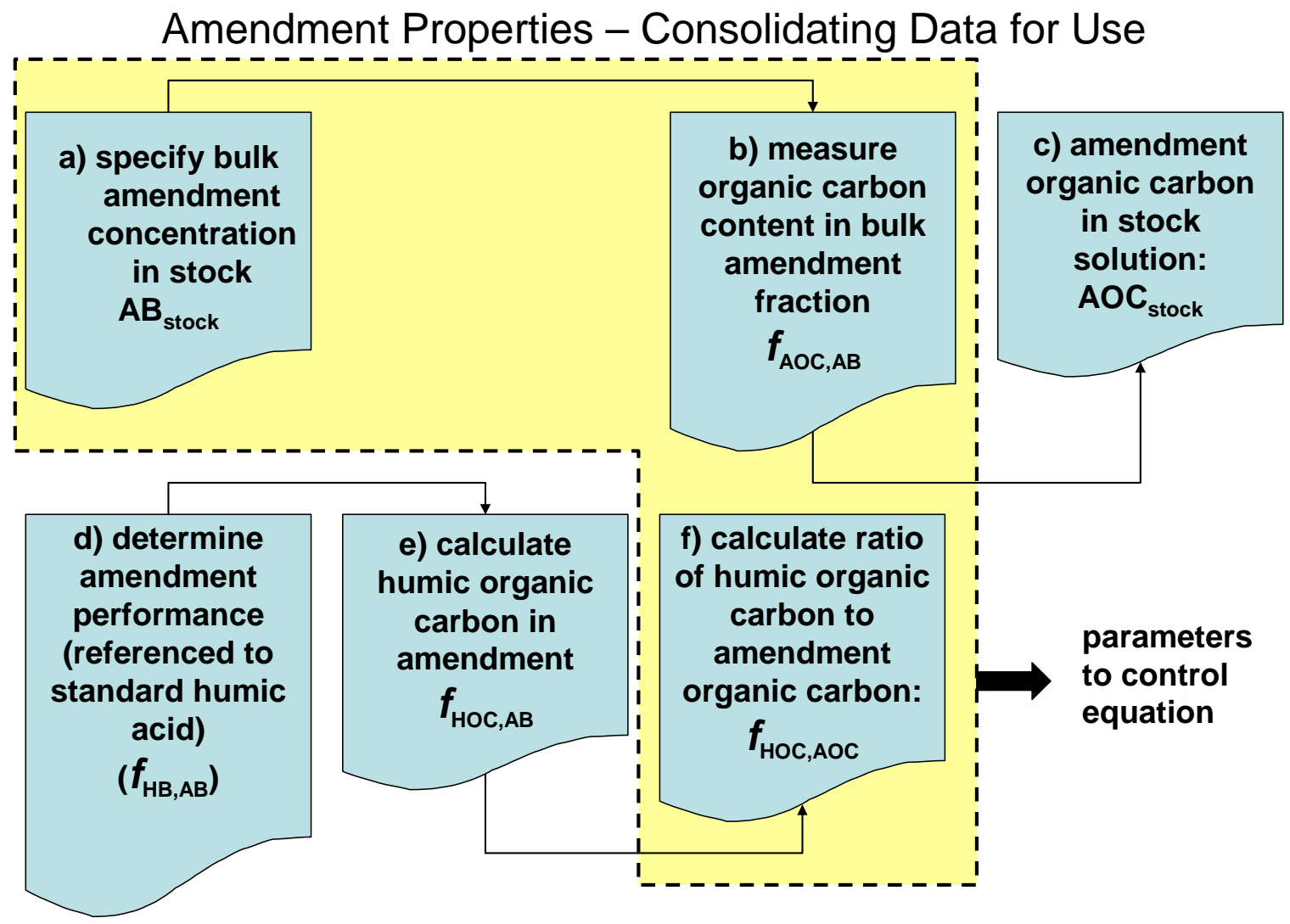

Figure 4. Flowchart of process to characterize potential amendments for use in the process control equation.

Table 3.

Tabulated Values for Control Equation for Potential Amendments

\begin{tabular}{|l|c|c|c|c|c|}
\hline Amendment & $A B_{\text {stock }}$ & $f_{\text {AOC,AB }}$ & $f_{\text {HB, AB }}$ & $f_{\text {HOC,HB }}$ & $f_{\text {HOC,AOC }}$ \\
\hline HumaK & 140,000 & 0.318 & 0.55 & 0.555 & 0.96 \\
\hline Borregro & 210,000 & 0.244 & 0.55 & 0.555 & 1.25 \\
\hline Vanisperse & 150,000 & 0.386 & 0.25 & 0.555 & 0.36 \\
\hline Humisolve & -- & 0.17 & $\mathrm{~nm}$ & -- & $0.96^{\star}$ \\
\hline Custom Sample & -- & 0.17 & $\mathrm{~nm}$ & -- & $0.96^{*}$ \\
\hline Mesa Verde Liquid & -- & 0.11 & $\mathrm{~nm}$ & -- & $0.96^{*}$ \\
\hline
\end{tabular}

* assumed to be similar to HumaK (i.e., standard humate extract) nm - not measured 
d) Determine amendment performance referenced to standard humic acid $\left(f_{\mathrm{HB}, \mathrm{AB}}\right)$. This parameter represents the ratio of the mass of equivalent standard humic acid to the mass of bulk amendment. The only way to determine a standardized performance is to actually measure the complexation of copper by the amendment and to determine the amount of humic acid that would provide the observed amount of complexation. To perform these tests, we used an ion specific electrode (ISE) for copper which measures only free (uncomplexed) copper. Since free copper and other labile forms of copper are the dominant aqueous species that contribute to toxicity, the copper electrode serves as a viable surrogate for the ecological receptors (i.e., gill tissue and other "biotic ligands"). For these tests, a low concentration copper solution was treated with ionic strength adjusting solution and titrated with each of the tested amendments and the response of the copper electrode was recorded. Based on the initial screening of amendments (Millings et al., 2008), three amendments were tested: HumaK, BorreGro HA1 and Vanisperse. The first two amendments are humates that are extracted from natural materials and processed for distribution and the third material is a lignosulfonate byproduct of pulp and paper processing. All of these materials are used in agriculture and soil conditioners and the humates are certified by the Organic Materials Review Institute (OMRI) for use in organic farming.

The resulting data for the three tested materials is provided in Tables 4-6 and plotted in Figures 5-7. The symbols in these figures represent the laboratory measurements and the lines are fitted models in which the fitting parameter is the $f_{\mathrm{HB}, \mathrm{AB}}$. Because of the use of nitrate containing ionic strength adjusting solution (a standard protocol for reliable measurements with the copper ISE), the modeling for this particular activity was performed with the Windermere Humic Aqueous Model (WHAM), version 6. The calculations in the BLM are a subset of those in WHAM but the BLM does not include nitrate as an available solution constituent. WHAM provided consistency with the BLM, particularly in terms of humic acid complexation and the associated geochemical coefficients, and also provided enhanced capability to properly model the laboratory tests. The model allowed the complexation capabilities of each amendment to be carefully referenced to standard humic acid precisely as quantified in the BLM/WHAM.

Both of the tested humates, which contain primarily humic and fulvic acids, behaved exactly as predicted in the model for standard humic acid with a $f_{\mathrm{HB}, \mathrm{AB}}$ of 0.55 (i.e., $55 \%$ of the bulk amendment is actively complexing copper equivalent to standard humic acid - the remainder of the amendment consisting of potassium, hydroxide, and other materials). The model fit to the data for the humate amendments was excellent over the entire $\mathrm{pH}$ range. Vanisperse is a lignosulfonate, a class of natural material related to humic acid. The best fit for Vanisperse indicated a significantly lower complexation capability (a $f_{\mathrm{HB}, \mathrm{AB}}$ of 0.25 ) and a less accurate model fit with underpredictions at low $\mathrm{pH}$ and overpredictions at higher $\mathrm{pH}$. The data suggested that the tested lignosulfonate is not functionally equivalent to humic acid. 
Table 4.

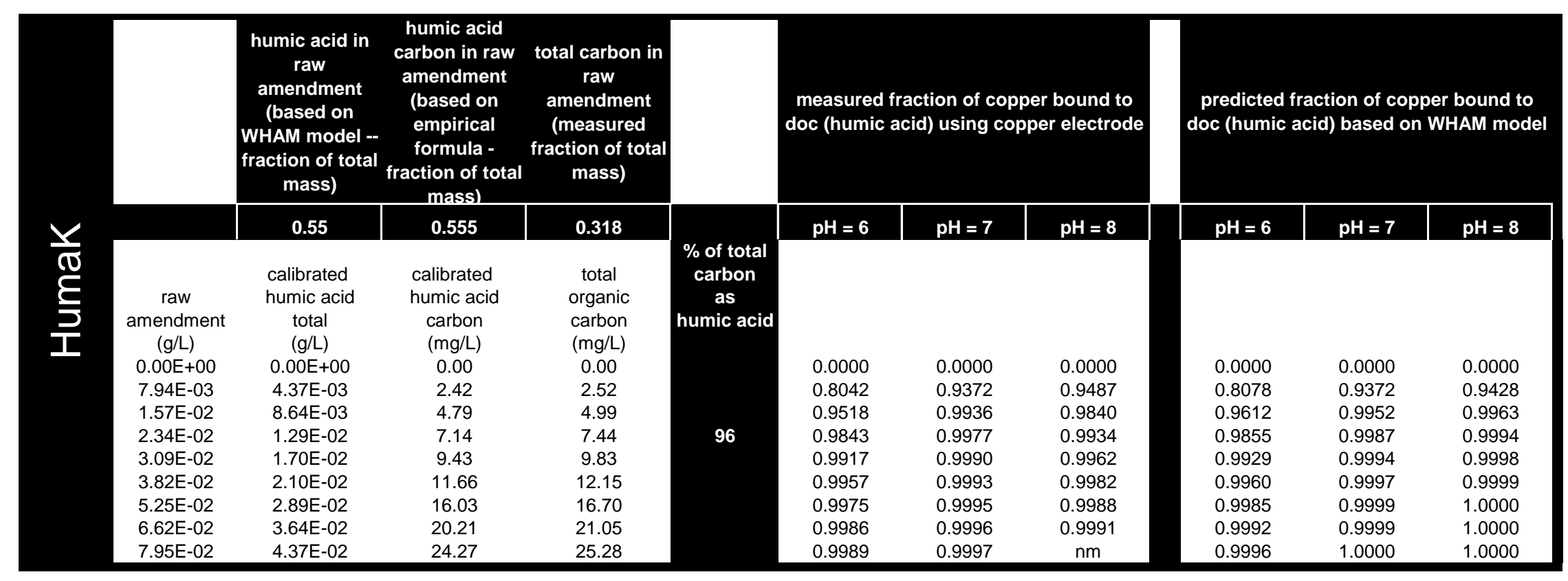




\section{HumaK Characterization Using Copper Electrode}

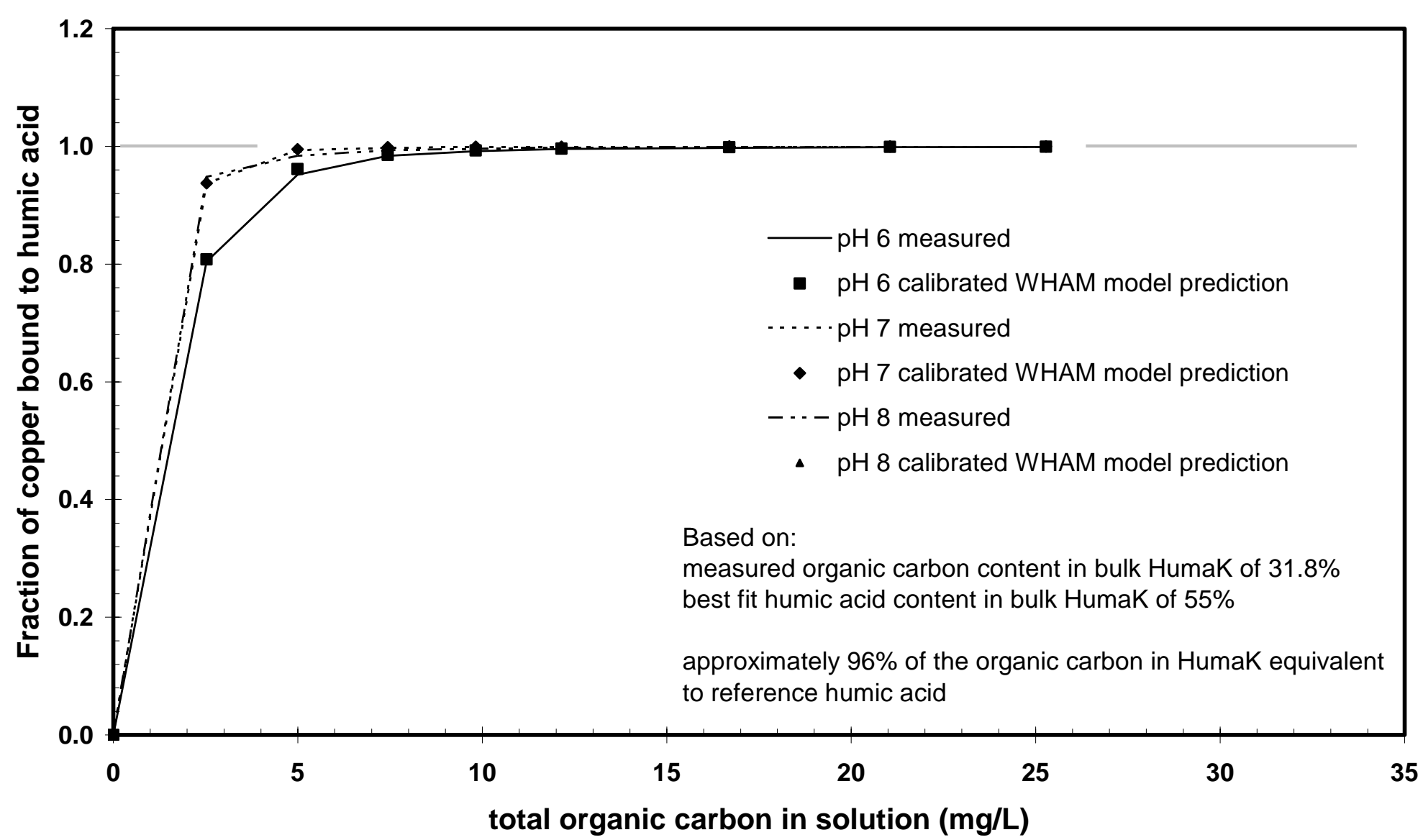

Figure 5. Electrode Study Data and Modeling Results for HumaK 
Table 5.

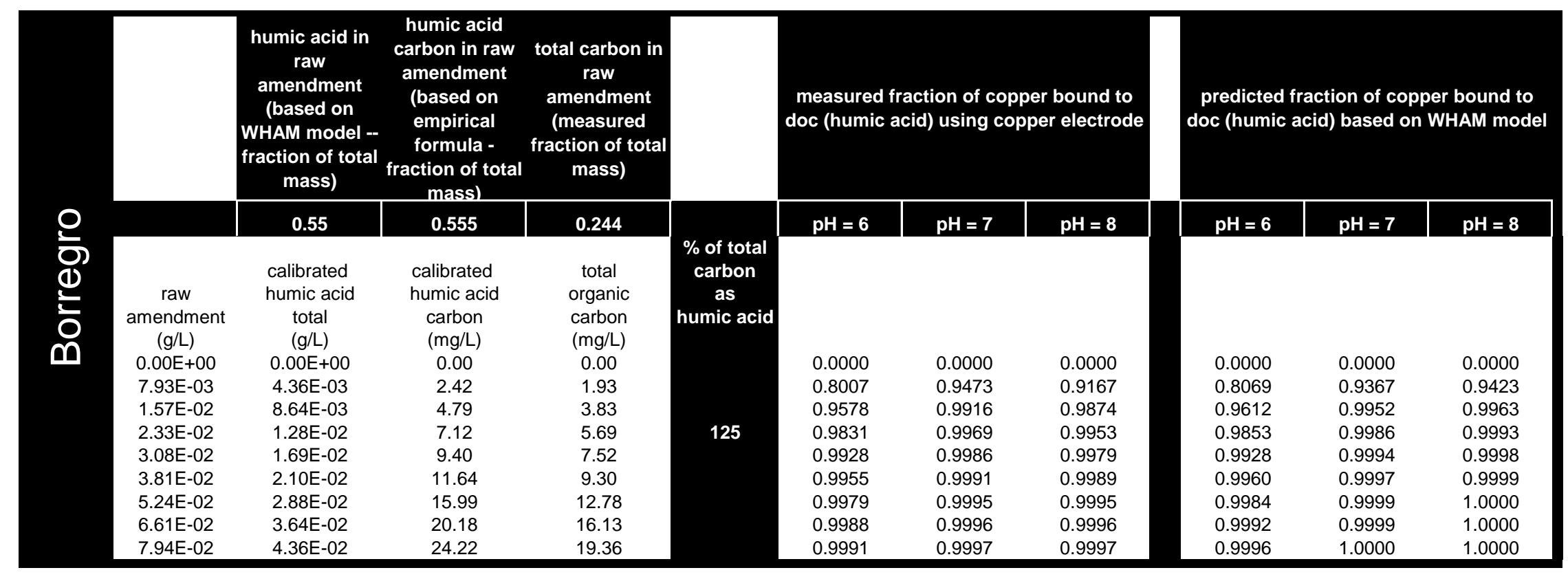




\section{Borregro Characterization Using Copper Electrode}

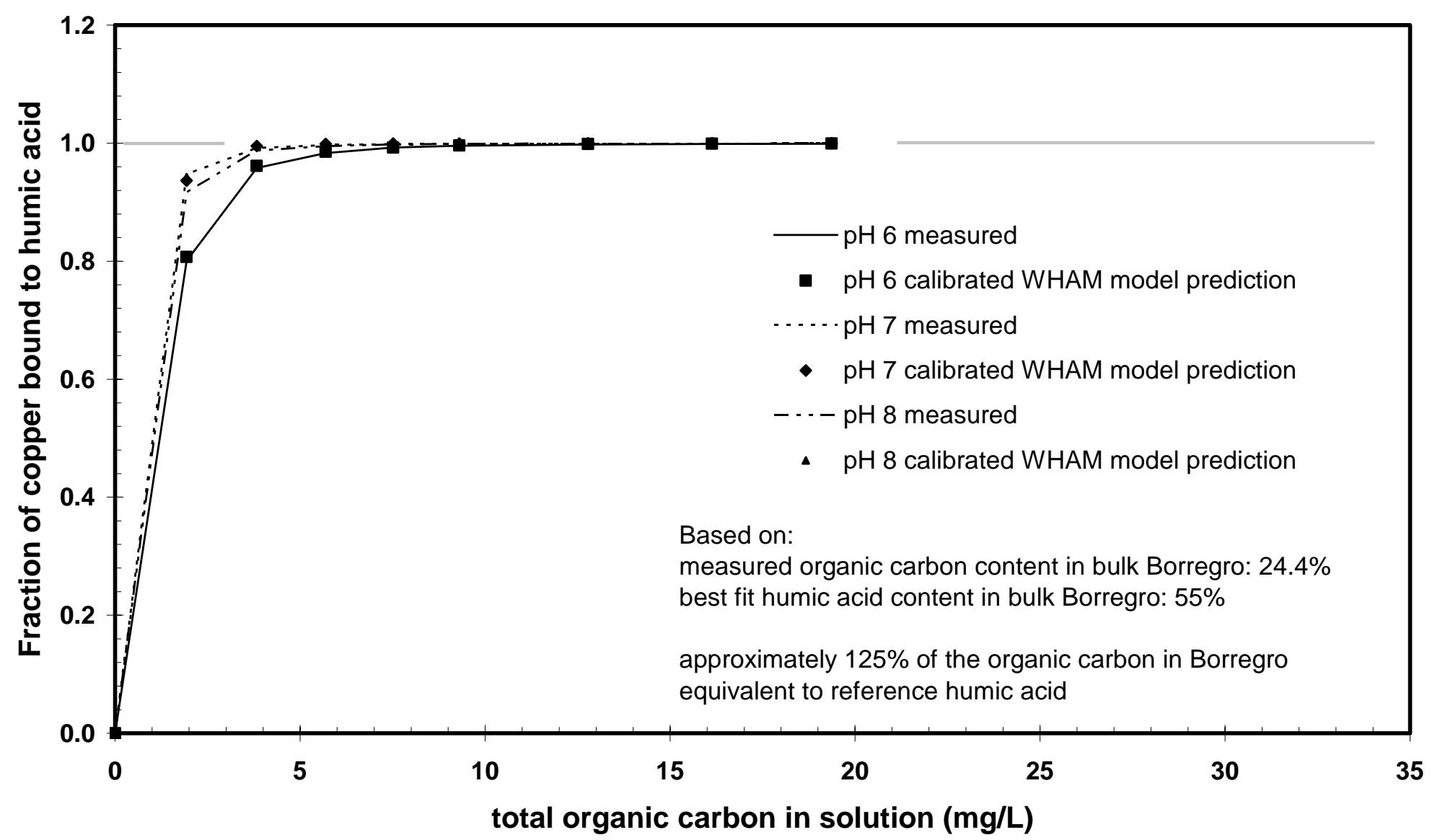

Figure 6. Electrode Study Data and Modeling Results for BorreGro HA1 
Table 6.

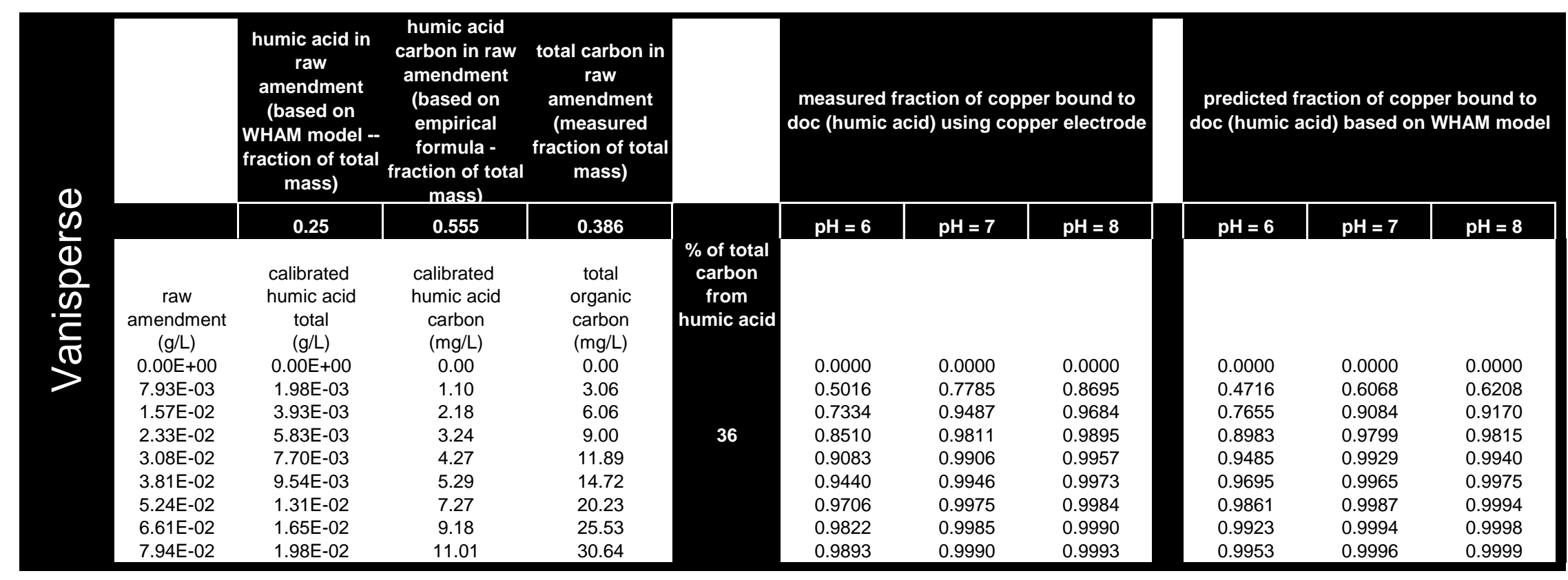




\section{Vanisperse Characterization Using Copper Electrode}

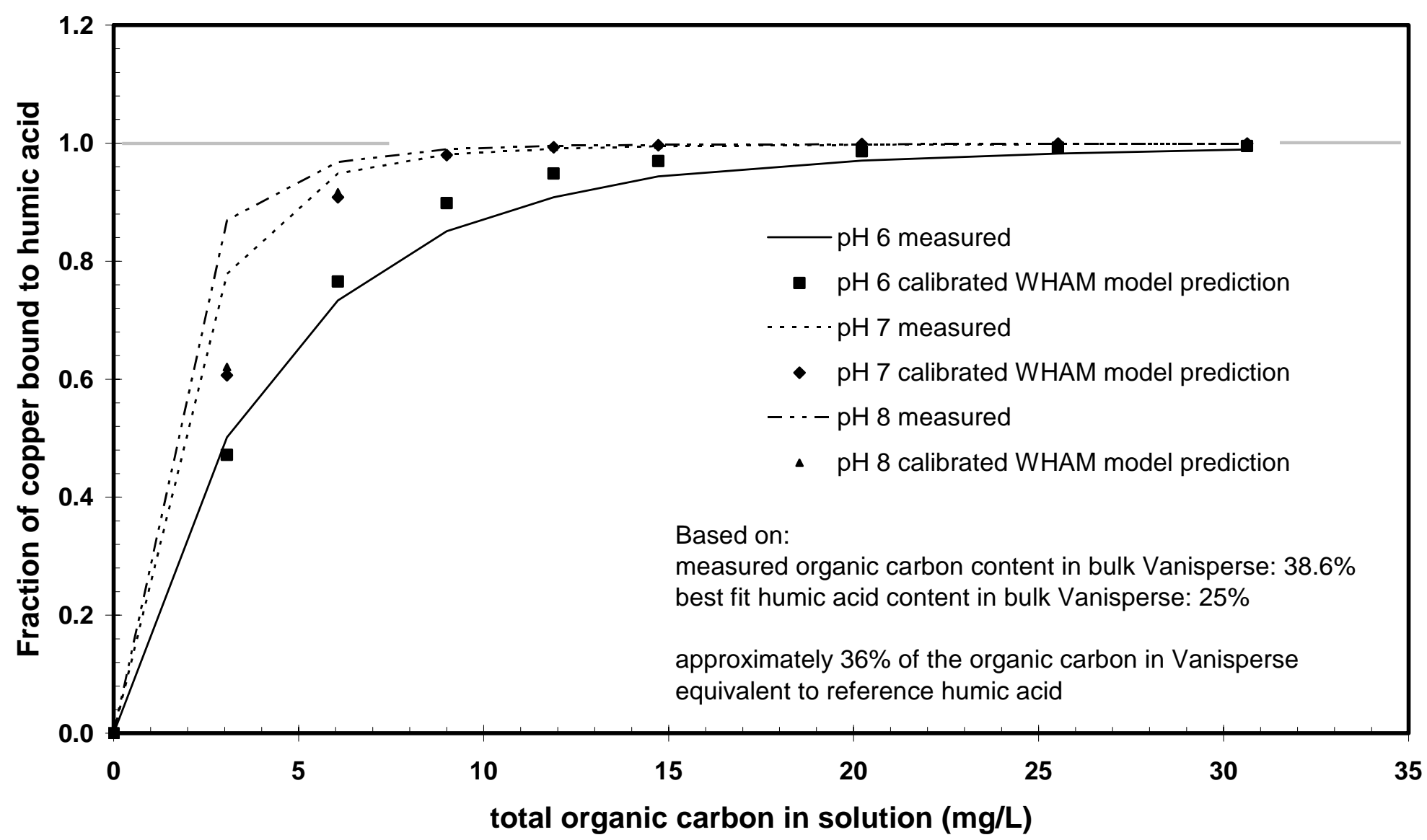

Figure 6. Electrode Study Data and Modeling Results for Vanisperse 
e) Determine the humic organic carbon content of the amendments ( $f_{\text {HOC,AOC). This }}$ parameter represents the ratio of the mass of humic organic carbon to amendment organic carbon:

$f_{\text {HOC,AOC }}=f_{\text {HOС, }, \mathrm{AB}} / f_{\mathrm{AOC}, \mathrm{AB}}$

In this calculation the $f_{\mathrm{AOC}, \mathrm{AB}}$ was calculated in step $\mathrm{b}$ and the $f_{\mathrm{HOC}, \mathrm{AB}}$ term is calculated using the $f_{\mathrm{HB}, \mathrm{AB}}$ from step d combined with the approximate carbon content of standard humic acid $\left(f_{\mathrm{HOC}, \mathrm{HB}}\right)$ of 0.55 (i.e., humic acid contains about $55 \%$ carbon by weight):

$f_{\mathrm{HOC}, \mathrm{AB}}=\left(f_{\mathrm{HB}, \mathrm{AB}}\right)\left(f_{\mathrm{HOC}, \mathrm{HB}}\right)$

The resulting values for all of the parameters for the various amendments are summarized in Table 3 and presented in detail in Tables 4-6. The $f_{\mathrm{HOC}, \mathrm{AOC}}$ is 0.36 for Vanisperse a lignosulfonate (this relatively low value indicating that the bulk of the carbon in Vanisperse is not involved in complexing copper and that this material is dissimilar to humic acid). Conversely, the $f_{\mathrm{HOC}, \mathrm{AOC}}$ is 0.96 for HumaK (suggesting that $96 \%$ of the carbon in this amendment can be characterized as humic acid) and 1.25 for BorreGro HA1 indicating a slightly higher complexation capacity for the carbon in this amendment than standard humic acid. This increased complexation results from a different extraction and processing regime that increases the presence of sulfonate functional groups (this processing also results in a slightly higher solubility as reflected in the higher $\mathrm{AB}_{\text {stock}}$ ).

As depicted in Figure 4 , the $f_{\mathrm{HOC}, \mathrm{AOC}}$ is considered a key property of the amendment that is used in the process control equation. 


\section{Putting it together -- the overall process control equation}

The previous activities result in a relatively simple approach to assemble the final consolidated process control equation. In concept, the equation is as follows:

Metering pump flow $=$ outfall flow $\frac{\text { required HOC dose concentration in outfall }}{\text { stock solution HOC concentration }}$

In this equation the numerator and denominator of the fraction are both in concentration units (mg HOC / L) and the fraction represents the required flow relationship (ratio between the metering pump and the outfall). The outfall flow is then used as an overall scalar to determine metering pump flow. Mathematically, this equation is summarized in Figure 7.

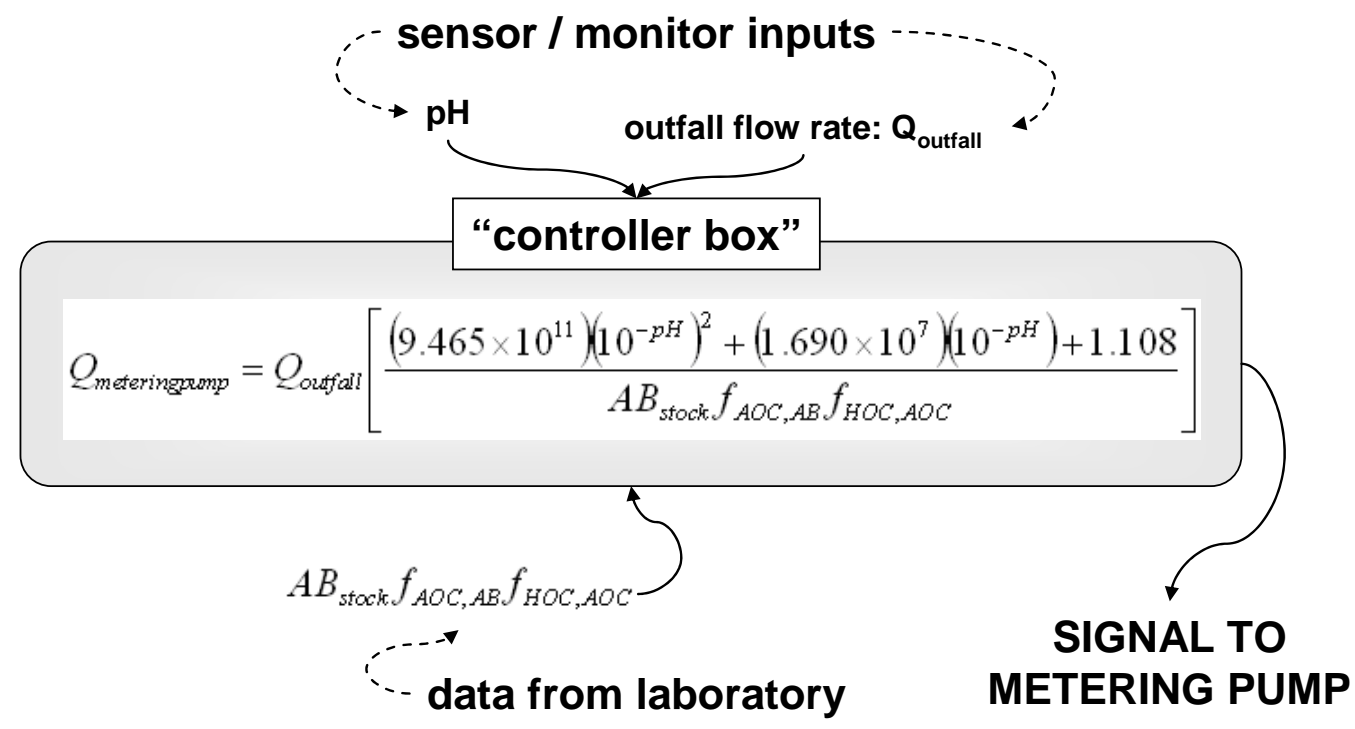

Figure 7. Summary of Process Control Equation

The numerator of the fraction is the polynomial dose equation developed above and the denominator represents the stock solution HOC concentration based on the various laboratory measurements. Required sensor/monitor inputs are $\mathrm{pH}$ and outfall flow (shown above the hypothetical controller box) and required information from laboratory measurements are designated below the box. Note that this equation results in a metering pump flow in the same units as the outfall flow (i.e., gpm). For a metering pump flow in traditional gph units, the result would be multiplied by 60 . Figure 8 is a screenshot of a spreadsheet that calculates metering pump flow for a variety of example $\mathrm{pH}$ and outfall flow scenarios for an example amendment (BorreGro HA1). Figure 8 indicates that the required amendment needed to mitigate toxicity increases significantly at low $\mathrm{pH}$ suggesting that it would be prudent to operate the facility to maintain circum-neutral $\mathrm{pH}$ in the water discharged to the outfall to the extent practicable. The calculated metering pump flow rates range widely depending on conditions with maximum values above 100 gph. 


\begin{tabular}{|c|c|c|c|c|}
\hline \multicolumn{5}{|c|}{ Sample calculations of metering pump flow rate } \\
\hline \multirow{3}{*}{\multicolumn{2}{|c|}{$\begin{array}{l}\text { Amendment }= \\
\text { ratio of humic acid organic carbon to total organic carbon in amendment }\left(f_{H O C, A O C}\right)= \\
\text { ratio of organic carbon in bulk amendment to total amendment }\left(f_{A O C, A B}\right)=\end{array}$}} & BorreGro HA-1 & \multirow{3}{*}{\multicolumn{2}{|c|}{$\begin{array}{l}\text { from lab measurement of copper complexation } \\
\text { from lab measurement of organic carbon }\end{array}$}} \\
\hline & & 1.250 & & \\
\hline & & 0.244 & & \\
\hline \multicolumn{2}{|c|}{ Stock solution concentration $=$} & 210000 & \multicolumn{2}{|c|}{ mg bulk amendment / L stock solution } \\
\hline \multirow{2}{*}{ pH } & \multirow{2}{*}{$\begin{array}{l}\text { bulk } \\
\text { amendment dose } \\
\text { mg/L }\end{array}$} & \multirow{2}{*}{$\begin{array}{l}\text { outfall } \\
\text { flow } \\
\text { gpm }\end{array}$} & \multicolumn{2}{|c|}{$\begin{array}{c}\text { metering pump } \\
\text { flow }\end{array}$} \\
\hline & & & gpm & gph \\
\hline 6.00 & 62.15 & 1000 & 0.30 & 17.76 \\
\hline 6.50 & 21.47 & 1000 & 0.10 & 6.13 \\
\hline 7.00 & 9.20 & 1000 & 0.04 & 2.63 \\
\hline 7.50 & 5.39 & 1000 & 0.03 & 1.54 \\
\hline 8.00 & 4.19 & 1000 & 0.02 & 1.20 \\
\hline 6.00 & 62.15 & 3000 & 0.89 & 53.27 \\
\hline 6.50 & 21.47 & 3000 & 0.31 & 18.40 \\
\hline 7.00 & 9.20 & 3000 & 0.13 & 7.89 \\
\hline 7.50 & 5.39 & 3000 & 0.08 & 4.62 \\
\hline 8.00 & 4.19 & 3000 & 0.06 & 3.59 \\
\hline 6.00 & 62.15 & 7000 & 2.07 & 124.29 \\
\hline 6.50 & 21.47 & 7000 & 0.72 & 42.93 \\
\hline 7.00 & 9.20 & 7000 & 0.31 & 18.41 \\
\hline 7.50 & 5.39 & 7000 & 0.18 & 10.78 \\
\hline 8.00 & 4.19 & 7000 & 0.14 & 8.37 \\
\hline
\end{tabular}

Figure 8. Example calculations of metering pump flow using polynomial based composite process control equation 


\section{References}

HydroQual, Inc, 2007. User's Guide and Reference Manual for Biotic Ligand Model, Windows Interface, Version 2.2.1, February 2007. Available from the U.S. Environmental Protection Agency, Washington DC.

Millings, M.R., B.B. Looney, N.V. Halverson and R.L. Nichols, 2009. Detoxification of Copper in Surface Water Discharges Using Soluble Humic Acid Amendment: Technical Summary of Results. WSRC-STI-2008-00105, Available from the U.S. Department of Energy Office of Scientific and Technical Information (OSTI), Oak Ridge TN, www.osti.gov. 